\title{
ASSESSING REGULATORY FOCUS DIFFERENCES IN CREATIVE IDEATION: AN EXAMINATION OF PREVENTION AND PROMOTION MINDSETS ON NOVELTY AND USEFULNESS
}

\author{
Meurzec, Rianne Wally (1); Koh, Brandon (2); Koronis, Georgios (1); Kang, Jacob Kai Siang (1); \\ Yogiaman, Christine (1); Silva, Arlindo (1) \\ 1: Singapore University of Technology and Design; 2: Singapore Management University
}

\begin{abstract}
The purpose of this work is to compare impact of regulatory focuses, namely preventive and promotional contexts, on creative ideation measured by novelty and usefulness. The study consisted of Singaporean students from an undergraduate university, and assessed their personality using the Big Five, Regulatory Focus, Creativity type and creativity outcomes measured with the Consensual Assessment Technique by completing a Collaborative Sketch exercise. Participants were randomly assigned to either the preventive, promotional or a baseline condition and tasked with a design problem necessitating a solution in the form of sketches. This study found the three conditions to yield significantly different novelty scores, but not usefulness scores. The most impactful condition on novelty was the baseline, indicating novice designers are capable of creating novel products and services. Those in the promotion condition created the second most novel sketches, or design solutions, followed lastly by the prevention condition. This may be so as novice designers consider larger space of solutions and may generate more ideas. This research is useful in creative pedagogy and for design professionals.
\end{abstract}

Keywords: Design cognition, Design education, Human behaviour in design

\section{Contact:}

Meurzec, Rianne Wally

Singapore University of Technology and Design

International Design Center

Singapore

riannemeurzec@hotmail.com

Cite this article: Meurzec, R.W., Koh, B., Koronis, G., Kang, J.K.S., Yogiaman, C., Silva, A. (2019) 'Assessing

Regulatory Focus Differences in Creative Ideation: An Examination of Prevention and Promotion Mindsets on Novelty and Usefulness', in Proceedings of the 22nd International Conference on Engineering Design (ICED19), Delft, The Netherlands, 5-8 August 2019. DOI:10.1017/dsi.2019.8 


\section{INTRODUCTION}

The study of creativity is broad, existing and flourishing across disciplines such as in the social sciences, manifesting in psychology and sociology, as well as in sciences such as architecture, engineering and design. Amabile posited in 1983 that social and environmental factors accounted for a striking amount of influence on creativity in individuals. She asserted the need for creativity research in social psychology to address the interaction of social and environmental factors with personality characteristics and cognitive abilities on observable creativity. Since 1983, much research has gone into exploring this dearth (Amabile, 1996; Hennessey, 2003; Amabile and Pillemer, 2012), and progressed the understanding of creativity as a construct, as well as methods of stimulation or inhibition for creative outcomes. A creative project is often initiated with a design brief. Yet, there is an absence in literature identifying what constitutes an effective design brief, and how its framing could impact the designers' creative cognition and outputs in terms of novelty and usefulness. To address this gap, we experimentally manipulated the framing of design briefs according to a promotion or prevention focus, and also measured participants' personalities and their creative approaches. This research is important to improve communication between clients and designers, in attaining creative products or services and satisfying client expectations. This paper explores the existing literature on personality and stimulation of creativity, before describing the study, and identifying the implications. To the best of our knowledge, our research is the first to experimentally manipulate design brief framing, while simultaneously considering the interactions with personality and its downstream psychological and creative consequences.

\section{BACKGROUND}

\subsection{Creativity}

Amabile (1994) outlines the two questions needed to carefully capture creativity in essence. The first question is what differentiates ordinary performance from creative performance; while the second is what personal ability and characteristics, social environments or other conditions are most favourable to creative performance. These questions are useful in developing our understanding of creativity, but also in adopting a framework for which to test and measure creativity. Ma (2009) explores creativity as a personality trait, a product and a process. Harnessing from this view, we aimed to understand the personality profiles of our participants with scales such as the Big Five, Regulatory Focus Scale, and Incremental Radical Creativity. We hoped to manipulate their environment by providing design briefs from varying conditions, namely baseline, prevention and promotion. Finally, we hope to see the effect on creativity, measured by Amabile's Consensual Assessment Technique, with the metrics of novelty and usefulness. The research model for our study is illustrated in Figure 1, demonstrating the independent variables of personality constructs, as well as the three conditions, and the Consensual Assessment Technique as dependent variable.

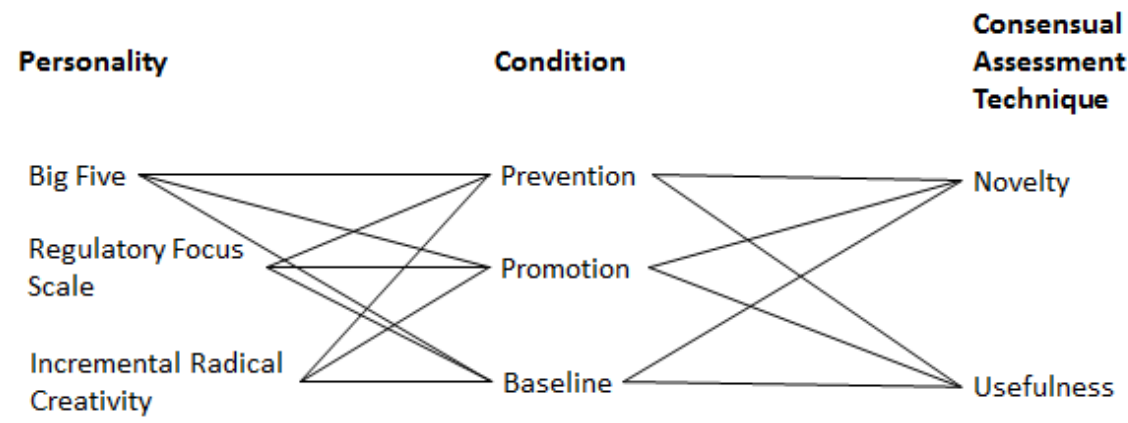

Figure 1. Research model

\subsection{Big five}

The Big Five personality assessment tool is one that has been widely used, in the fields of psychology, sociology and the social sciences. It has been used as a tool to ascertain job performance (Barrick and Mount, 1991), academic performance (Trapmann et al., 2007; Poropat, 2009) and career choices 
(Zhao and Seibert, 2006; Bono and Judge, 2004). The Big Five refers to five constructs, or facets of personality, that define people, namely openness to experience (intellectual, imaginative, independentminded), conscientiousness (orderly, responsible, dependable), extraversion (talkative, assertive, energetic), agreeableness (good-natured, cooperative, trustful) and neuroticism (absence of calm, emotional instability) (John and Srivastava, 1999). The Big Five is a comprehensive framework (Goldberg, 1990) and is therefore, an intuitive starting point for personality research. One longitudinal study by Sung and Choi (2009) found that extraversion and openness to experience factors had a significant positive relationship on creative performance. Another study (Batey et al., 2010) found that the Big Five was a significant predictor of ideational behaviour, an indicator of creativity, explaining up to $22 \%$ of variance. Leung and Chiu $(2008,2010)$ also demonstrated that individuals with higher openness to experience are more adept at learning from multicultural experiences to generate more novel ideas. As part of our study, we hypothesized (H1) students with high openness to experience and extraversion would score highly on creativity indices.

\subsection{Regulatory focus questionnaire}

The Regulatory Focus theory (Higgins, 1997) suggests that persons rely on two distinct mindsets when pursuing their goals, namely promotion and prevention focuses. The promotion focus mindset sees individuals being driven by their ideals and seeking gains while avoiding situations where no gain is earned. Contrastingly, prevention focused individuals are driven by their obligations or duties, and seek to avoid loss, or maintenance of status quo (Higgins, 1997). As such, the theory proposes that the framing of a task interacts with an individuals' mindset, thereby either intensifying or disrupting their motivation in task performance. Where mindset and task framing align, a condition known as "regulatory fit" emerges, illustrating that individuals feel right about their goals, thus increasing their motivation and performance (Cesario, Higgins, and Scholer, 2008; Higgins, 2000). When applied to creativity, studies have found preventive mindset to be inhibitive of creativity (Baas, De Dreu, and Nijstad, 2008; Bittner and Heidemeier, 2013; Friedman and Förster, 2001). As such, we hypothesized (H2a) students with promotion focused mindsets would do better in promotion-oriented tasks (i.e. with the exposure to promotion focused design briefs). Alternatively, we also hypothesized (H2b) students with prevention focused mindsets would do better in prevention-oriented tasks (i.e. with the exposure to prevention focused design briefs).

\subsection{Incremental radical creativity}

Another aspect of creativity research deemed useful in this space is the type of creativity that is stimulated. Gilson and Madjar (2011) determined two distinct types of creativity, namely radical creativity associated with exploring completely new ideas and producing game-changing innovations that do not resemble their point of origin, and incremental creativity associated with exploiting best available ideas to improve upon existing solutions. A study by Madjar et al. (2011) found that willingness to take risks, access to resources for creativity and career commitment are associated primarily with radical creativity, while the presence of creative co-workers and identification with the organization is associated with incremental creativity. As such, we hypothesized (H3) that promotion focused individuals would rank themselves as having higher radical creativity, while the prevention focused individuals would rank themselves as having higher incremental creativity.

\subsection{Consensual assessment technique}

According to Amabile (1996), creativity can be measured by novelty and appropriateness (usefulness, correctness, valuableness) when applied to a product or response. To do so, we employed the Consensual Assessment Technique (Amabile, 1996), a powerful tool that has been used across multiple studies for measuring creativity, under the metrics of novelty and usefulness. Our study employed the assessment technique detailed by Amabile, however, with a modified version of usefulness. Novelty was defined by the extent to which a design was different from usual forms of products and services on the domain under study. Usefulness was defined by a series of factors, namely Implementability, Effectiveness, Applicability, Ease of Use and Storage, and Affordability. The factors were selected following a literature review of the various definitions of usefulness (Dean et al., 2006). Our interest to use a modified version of the usefulness metric was to include a broader definition of usefulness, as the briefs presented participants with several possible interpretations. As 
such, we hoped to assess products and services rendered by participants with a broad enough metric of usefulness. The use of the Consensual Assessment Technique was helpful to provide a framework for expert and non-expert judges to assess C-Sketches, while maintaining a rigorous definition of creativity scores, namely novelty and usefulness. We hypothesized (H4) that significant differences would exist on creativity scores (measured with novelty and usefulness) between conditions (prevention, promotion and baseline groups).

\section{METHODOLOGY}

\subsection{Design and participants}

Participants were recruited from a local university specializing in technology and design, from a core first-year course called Introduction to Design. A total of 149 participants were recruited, aged from 17 to 24 years (mean age $=20$ years old), and consisted of $65 \%$ male and $35 \%$ female. Participants were randomly assigned to the baseline, promotion focused, or prevention focused conditions. In the baseline brief condition, they were given basic information surrounding a design task requesting their development of a mobility device for persons in low income brackets. In the promotion focus and prevention focused conditions, the same information was reframed to induce designers to think in terms of pursuing a design ideal, or to satisfy the design task's obligation, respectively (see Appendix).

\subsection{Measures}

\subsubsection{Big five}

The Big Five instrument (Soto and John, 2017) was completed by participants during the admission process into the university. It captures the personality factors of openness to experience, conscientiousness, extraversion, agreeableness and neuroticism, on a 5-point Likert scale indicating agreement. The university classes are calibrated to include a mix of student profiles.

\subsubsection{Regulatory focus questionnaire}

The Regulatory Focus questionnaire (Lockwood, Jordan and Kunda, 2002) was administered online as part of the pre-survey. This scale captures participants promotion and prevention focus traits as independent factors. An example promotion item includes "I typically focus on the success I hope to achieve in the future", and a prevention item includes "I frequently think about how I can prevent failures in my life". The Regulatory Focus questionnaire uses a 5-point Likert scale to indicate agreement, and exhibited good internal reliability for both factors of prevention $(\alpha=0.79)$, and promotion $(\alpha=0.84)$.

\subsubsection{Incremental radical creativity}

The Incremental Radical Creativity (Gilson and Madjar, 2011) was administered online as part of the post-survey. The factors composing the Incremental Radical Creativity Scale showed acceptable alphas for the subscale of radical $(\alpha=0.82)$ and incremental $(\alpha=0.74)$ creativity.

\subsubsection{Consensual assessment technique}

The Consensual Assessment Technique (Amabile, 1996) is a tool we used in two ways. First, we used it to ask students to assess their peers' C-Sketches. Second, we used it as part of the expert judges' assessment of C-Sketches. The Consensual Assessment Technique amongst students showed good interrater consistency, as indicated by the one-way random intraclass correlation, ICC novelty $=0.78$, ICC usefulness $=0.89$. The five items of the Usefulness scale were subjected to an exploratory factor analysis using the Maximum likelihood method. The Kaiser-Meyer-Oklin value was 0.74, exceeding the recommended value of 0.6 (Kaiser, 1970) which indicates sampling adequacy. A single factor solution was extracted explaining $61 \%$ of the variance respectively, with all factor loadings exceeding .68. This supports that the usefulness scale measures a unidimensional construct.

\subsection{Procedures}

Participants completed a workshop as part of their university requirements. Participants worked in teams of 4 on average. They first completed an online pre-task survey investigating their dominant 
regulatory focus. Participants then received a design brief according to their experimental condition and were tasked to complete a C-Sketch (White, Wood \& Jensen, 2012) in their groups within 25 minutes. During the C-Sketch, participants were to generate and sketch a novel idea that would contribute to part of the group design. Every 5 minutes, their partial designs were rotated to the next team member. Each member continued to make edits and improvements until the C-Sketches returned to their original owners. After the C-Sketch exercise, participants completed a peer evaluation assessment using the Consensual Assessment Technique. In this task, participants in the sample evaluated the C-Sketches produced by other groups for their novelty and usefulness and on average rated approximately $4 \mathrm{C}$-Sketch sheets. Once the peer evaluation was completed, participants completed an online post-task survey, investigating their reception of the design brief, their motivation, and personality measures. Participants Big Five personality scores were obtained from the University entry survey archives.

\section{RESULTS}

This study had a sample size of 149 for the prevention, promotion and baseline groups, which yielded a total of 441 sketches. A summary of descriptive statistics is detailed in Table 1 displaying the sample size, mean and standard deviation of included variables.

Table 1. Descriptive statistics

\begin{tabular}{lccc}
\hline Category & N size & Mean & Standard deviation \\
\hline Baseline & 20 & & \\
Prevention & 59 & & \\
Promotion & 70 & & \\
\hline BF Openness & 132 & 2.05 & 0.94 \\
BF Conscientiousness & 132 & 2.04 & 0.97 \\
BF Extraversion & 132 & 1.72 & 0.90 \\
BF Agreeableness & 132 & 2.11 & 0.92 \\
BF Neuroticism & 132 & 2.14 & 0.91 \\
RFQ Promotion & 149 & 3.87 & 0.61 \\
RFQ Prevention & 149 & 3.48 & 0.69 \\
Incremental Radical & 149 & 3.91 & 0.49 \\
Creativity & & & \\
Novelty & 149 & 3.40 & 0.54 \\
Usefulness & 149 & 3.03 & 0.40 \\
\hline indicates Big Five scale; the "RFQ" prefix indicates Regulatory Focus Questionnaire
\end{tabular}

\subsection{Big five}

A detailed breakdown of student Big Five scores can be found in the Appendix.

\subsection{Regulatory focus questionnaire}

Our total sample exhibited a larger proportion of participants as having a promotional regulatory focus (64\%) compared to a preventive regulatory focus (30\%), and a small subset was tied between the two $(6 \%)$. Of those in the prevention design brief sample $(\mathrm{n}=59), 34 \%$ ranked dominantly in prevention focus, $61 \%$ ranked dominantly in promotion focus, and the rest tied between the two. Of those in the promotion design brief sample $(n=70), 29 \%$ ranked dominantly in prevention focus, $65 \%$ ranked dominantly in promotion focus, and the rest tied between the two.

\subsection{Incremental radical creativity}

Our total sample exhibited a larger proportion of participants as having incremental creativity (43\%) compared to radical creativity $(31 \%)$ and a large subset was tied between $(26 \%)$. Of those in the prevention design brief sample $(\mathrm{n}=59), 49 \%$ ranked dominantly in incremental creativity, $24 \%$ ranked dominantly in radical creativity, and the rest tied between the two. Of those in the promotion design brief sample $(n=70), 39 \%$ ranked dominantly in incremental creativity, 35\% ranked dominantly in radical creativity, and the rest tied between the two. 


\subsection{Model testing}

A one-way between-groups analysis of variance (ANOVA) was conducted to explore the relationship between personality metrics, regulatory focus, incremental radical creativity and creativity metrics (namely novelty and usefulness) by condition (specifically baseline, prevention and promotion groups). Only the novelty condition yielded significant differences. Subjects were divided into three groups according to the condition they were exposed to (Group 1: Baseline, Group 2: Prevention, Group 3: Promotion). There was a medium-sized main effect of experimental condition on Novelty scores, $\mathrm{F}(2,146)=9.27, \mathrm{p}<.001, \eta^{2}=.11$. Post-hoc comparisons using the LSD test indicated that the mean score for the baseline condition $(\mathrm{M}=3.82, \mathrm{SD}=0.46)$ was significantly higher on novelty score than the promotion focus condition $(\mathrm{M}=3.41, \mathrm{SD}=0.52)$; in turn, the promotion focus condition exhibited significantly higher novelty scores than the prevention condition $(\mathrm{M}=3.25, \mathrm{SD}=0.53)$. Figure 3 illustrates the means plot for Novelty across conditions.

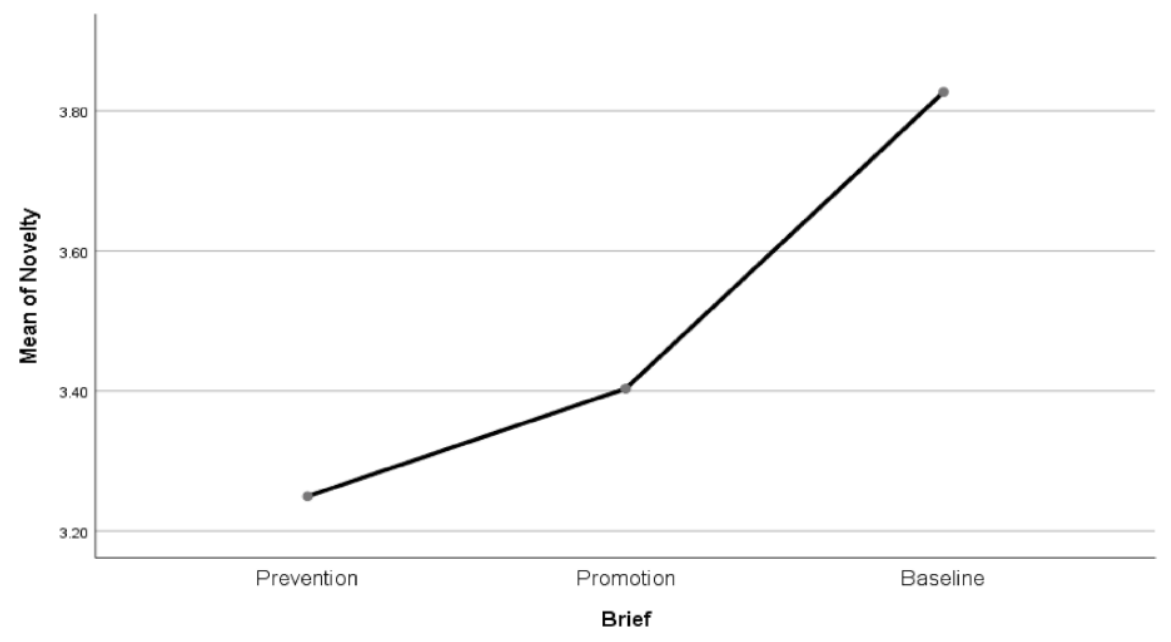

Figure 2. Means plot for Novelty across conditions

\section{DIscussion}

Our research project aimed to identify personality profiles, and whether the conditions of baseline, prevention and promotion framing would have an effect on creativity metrics, namely novelty and usefulness. It was found that within our sample, personality, regulatory focus and incremental radical creativity did not have an impact on the Consensual Assessment Technique creativity metrics. Usefulness was also psychometrically defined in a novel way, with the inclusion of implementability, efficacy, applicability, ease of storage and use, and affordability creating a score of usefulness. The measure of usefulness proved to be insignificantly different between the three conditions. Novelty, on the other hand, demonstrated a significant difference between the conditions, with the baseline condition yielding the highest novelty scored sketches, followed by the promotion condition and lastly, the prevention condition. In returning to our hypotheses, in H1, we expected but did not find openness to experience and extraversion to positively predict creativity scores. In H2a, we expected students with promotion focused mindsets on the regulatory focus questionnaire to do better at promotion-oriented tasks (those in the promotion condition), however, we found this not to be the case. In $\mathrm{H} 2 \mathrm{~b}$, we expected the inverse of $\mathrm{H} 2 \mathrm{a}$ for the prevention group, but similarly found this not to be true in our sample. Our third hypothesis posited that promotion focused individuals would have higher radical creativity, while prevention focused individuals would have higher incremental creativity. We found both groups to rank highest on incremental creativity, followed by radical creativity and lastly tied between both, thus disproving this hypothesis. Lastly, H4 hypothesized significant differences would exist between the design brief conditions and creativity indices. This hypothesis was proven correct, with novelty score demonstrating significant differences between the three conditions but was not held up for usefulness. Within the novelty score, the baseline condition scored highest, followed by promotion condition and lastly the prevention condition. It can be speculated that the reason for the baseline condition to yield the highest novelty score is because of the inherent vague nature of the baseline brief, allowing participants to interpret the design brief freely and 
without the pre-set of any regulatory focus. Considering our sample was that of first-year undergraduate students, it is perhaps correct to expect students from this background to be less fixated than senior students and practitioners, and to allow their creativity to construct sketches with originality. One study (Yuan et al., 2014) found that experts were found to be more practical, structured, detailed and had more control of actions during design, compared to their novice counterparts which were found to consider larger space of solutions and the ability to generate more ideas, though not realistic. The second most novel group, those within the promotion design brief condition, is unsurprisingly significant as students identified with a promotion regulatory focus at the highest proportion, followed by prevention and lastly, a tie between the two mindsets. As such, students were predisposed to be more promotion focused, and those in the promotion condition were more novel than their prevention counterparts.

\section{CONCLUSION AND FUTURE WORK}

The research conducted aimed to find relationships between personality (using the Big Five scale), Regulatory Focus, Incremental Radical Creativity and creativity scores (namely novelty and usefulness). The key finding of this research indicated that novelty yielded significantly different results between the three conditions, with the baseline condition yielding the highest novelty scores, followed by the promotion condition and lastly the prevention condition. The reason behind this may be that undergraduate students are less likely than professionals to be moulded and fixated mentally, thus allowing them to explore novel ideas more easily. Further, it is unsurprising that the promotion design brief condition yielded the second highest novelty scores, as the sample was mostly promotion focused, in regulatory focus. Limitations of this research include the small sample, and the fact that participants were undergraduate students, thus perhaps limiting the applicability of findings to a more senior professional population. This study would benefit from a second set of creativity scores, which would have been well served with the expert judges' ratings. This research may prove useful to the pedagogy of design and creativity to student designers, as well as design and architect professionals. Lastly, this research may be impactful for those seeking design work, to optimize communication of their needs and desires and maximize the creative outcomes of design. Future research in this field can replicate this study with the use of older participants, and professionals in larger numbers to provide comparative results.

\section{REFERENCES}

Amabile, T.M. (1983), “The social psychology of creativity: A componential conceptualization.” Journal of personality and social psychology, Vol. 45 No. 2, p. 357.

Amabile, T.M. (1996), Creativity in Context (Westview, Boulder, CO).

Amabile, T.M. and Pillemer, J. (2012), "Perspectives on the social psychology of creativity." The Journal of Creative Behavior, Vol. 46 No. 1, pp. 3-15.

Baas, M., De Dreu, C.K. and Nijstad, B.A. (2008), “A meta-analysis of 25 years of mood-creativity research: Hedonic tone, activation, or regulatory focus?.” Psychological bulletin, Vol. 134 No. 6, p. 779.

Barrick, M.R. and Mount, M.K. (1991), "The big five personality dimensions and job performance: a metaanalysis." Personnel psychology, Vol. 44 No. 1, pp. 1-26.

Bartlett, M.S. (1954), “A note on the multiplying factors for various $\chi 2$ approximations.” Journal of the Royal Statistical Society. Series B (Methodological), pp. 296-298.

Batey, M., Chamorro-Premuzic, T. and Furnham, A. (2010), "Individual differences in ideational behavior: Can the big five and psychometric intelligence predict creativity scores?." Creativity Research Journal, Vol. 22 No. 1, pp. 90-97.

Bittner, J.V. and Heidemeier, H. (2013), "Competitive mindsets, creativity, and the role of regulatory focus." Thinking skills and creativity, Vol. 9, pp. 59-68.

Bono, J.E. and Judge, T.A. (2004), "Personality and transformational and transactional leadership: a metaanalysis." Journal of applied psychology, Vol. 89 No. 5, p. 901.

Cesario, J., Higgins, E.T. and Scholer, A.A. (2008), "Regulatory fit and persuasion: Basic principles and remaining questions." Social and Personality Psychology Compass, Vol. 2 No. 1, pp. 444-463.

Dean, L.D., Hender, J.M., Rodgers, T.L., and Santanen, E.L. (2006), "Identifying quality, novel, and creative ideas: constructs and scales for idea evaluation1." Journal of the Association for Information Systems, Vol. 7 No. 10, p. 646.

Friedman, R.S. and Förster, J. (2001), "The effects of promotion and prevention cues on creativity." Journal of personality and social psychology, Vol. 81 No. 6, p. 1001. 
Gilson, L.L. and Madjar, N. (2011), "Radical and Incremental Creativity: Antecedents and Processes. Psychology of Aesthetics", Creativity and the Arts, Vol. 5 No. 1, pp. 21-28.

Goldberg, L. R. (1990), “An alternative "description of personality”: the big-five structure.” Journal of personality and social psychology, Vol. 59 No. 6, p. 1216.

Hennessey, B.A. (2003), “The social psychology of creativity." Scandinavian Journal of Educational Research, Vol. 47 No. 3, pp. 253-271.

Higgins, E.T. (1997), "Beyond pleasure and pain.” American psychologist, Vol. 52 No. 12, p. 1280.

Higgins, E.T. (2000), "Making a good decision: value from fit.” American psychologist, Vol. 55 No. 11, p. 1217.

John, O.P. and Srivastava, S. (1999), "The Big Five trait taxonomy: History, measurement and theoretical perspectives." Handbook of personality: Theory and research, Vol. 2 No. 1999, pp. 102-138.

Kaiser, H.F. (1970), “A second generation little jiffy.” Psychometrika, Vol. 35 No. 4, pp. 401-415.

Leung, A. K.-y., and Chiu, C.-y. (2008), "Interactive effects of multicultural experiences and openness to experience on creative potential.” Creativity Research Journal, Vol. 20 No. 4, 376-382.

Leung, A. K.-y., and Chiu, C.-y. (2010), "Multicultural experience, idea receptiveness, and creativity." Journal of Cross-Cultural Psychology, Vol. 41 No. 5-6, 723-741.

Lockwood, P., Jordan, C.H., and Kunda, Z. (2002), "Motivation by Positive or Negative Role Models: Regulatory Focus Determines Who Will Best Inspire Us.” Journal of Personality and Social Psychology, Vol. 83 No. 4, pp. 854-864.

Ma, H.H. (2009), "The effect size of variables associated with creativity: A meta-analysis." Creativity Research Journal, Vol. 21 No. 1, pp. 30-42.

Poropat, A.E. (2009), "A meta-analysis of the five-factor model of personality and academic performance." Psychological bulletin, Vol. 135 No. 2, p. 322.

Soto, C.J. and John, O.P. (2017), "The next Big Five Inventory (BFI-2): Developing and assessing a hierarchical model with 15 facets to enhance bandwidth, fidelity, and predictive power." Journal of Personality and Social Psychology, Vol. 113 No. 1, p. 117.

Sung, S.Y. and Choi, J.N. (2009), "Do Big Five personality factors affect individual creativity?" The moderating role of extrinsic motivation. Social Behavior and Personality: an international journal, Vol. 37 No. 7, pp. 941-956.

Trapmann, S., Hell, B., Hirn, J.O.W. and Schuler, H. (2007), "Meta-analysis of the relationship between the Big Five and academic success at university." Zeitschrift für Psychologie/Journal of Psychology, Vol. 215 No. 2, pp. 132-151.

White, C.K., Wood, K.L. and Jensen, D. (2012), "From brainstorming to C-sketch to principles of historical innovators: ideation techniques to enhance student creativity." Journal of STEM Education: Innovations and Research, Vol. 13 No. 5.

Yuan, J.T.J., Kong, K.Y., Parveen, H., Zhixiang, H., Rajasekaran, G., Behera, J.K., Sanaei, R., Otto, K.N., and Holtta-Otto, K. (2014), An overview of design cognition between experts and novices. ICADRE 2014.

Zhao, H. and Seibert, S.E. (2006), "The Big Five personality dimensions and entrepreneurial status: A metaanalytical review." Journal of applied psychology, Vol. 91 No. 2, p. 259.

\section{ACKNOWLEDGMENTS}

This work is supported by the Singapore University of Technology and Design (SUTD) and the SUTD-MIT International Design Centre (IDC, idc.sutd.edu.sg), project IDG 11600102. The authors thank Nilanjan Raghunath and Pei Zhi Chia for their input, and the 2018 batch of first-year undergraduate student-designers for their ideation efforts and collaboration. 


\section{APPENDIX}

\section{Design Task Instructions}

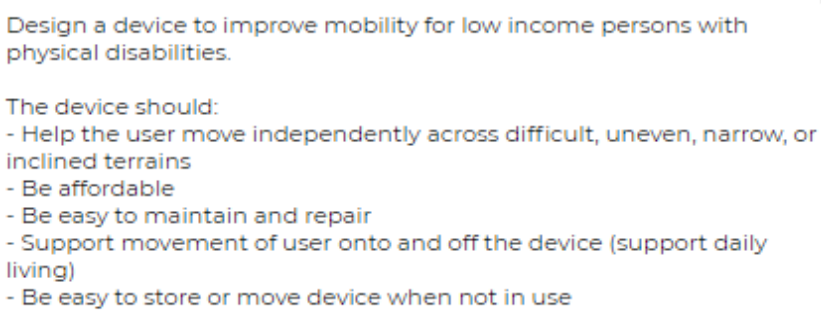

\section{Baseline brief}

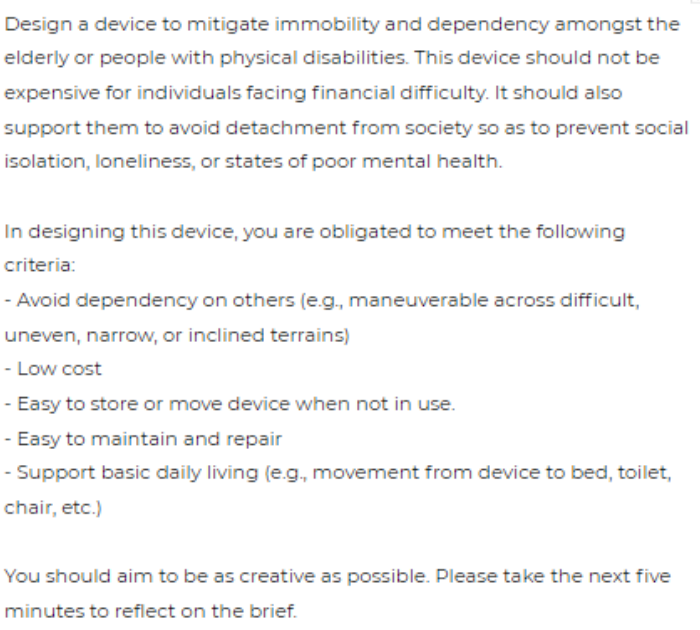

Design a device that can enhance physical mobility and enable independence amongst the elderly or people with physical disabilities This device should be inclusive for individuals of all social classes, including the poor. It should also help them integrate into the broader society so that they can enhance their social and psychological well-being.

In designing this device, you can aspire to achieve the following criteria: - Enhance individual mobility (e.g., maneuverable across difficult, uneven, narrow, or inclined terrains

- Inclusive for all social classes, including the poor

Easy to store or move device when not in use.

Easy to restore to working condition

Empower independence (e.g., movement from device to bed, toilet, chair, etc.).

You should aim to be as creative as possible. Please take the next five minutes to reflect on this brief.

\section{Promotion design brief}

Prevention design brief

Openness

(ack of Direction

Student big five scores 
